\title{
Update
}

\section{Antipsychotic switching tool [Update]}

Aust Prescr 2019;42:213

https://doi.org/10.18773/austprescr.2019.072

First published 29 October 2019

The online tool by Nicholas Keks et al has been updated. View updated tool.

The risperidone depot switches to aripiprazole and flupentixol have been updated to include recommendations to start at $25 \%$ of the target dose if starting within 3 weeks of the last injection of risperidone. All risperidone depot switches, except the switch to paliperidone, include extra clarification for this recommendation.

The source material used for the tool has also been included.

\section{EDITORIAL OFFICE}

For general correspondence such as Letters to the Editor, contact the Editor.

Postal The Editor

Australian Prescriber

Level 5, 15 Moore Street

Canberra, ACT 2600

Telephone +61282178700

Email_info@australianprescriber.com

Website nps.org.au/australian-prescriber

Twitter@AustPrescriber

\section{SUBSCRIPTIONS}

Australian Prescriber is published every two months online. All content is accessible free of charge in full text at nps.org.au/ australian-prescriber. New drugs are published between issues as they become available.

An email alert can be sent to you when Australian Prescriber publishes new material. Subscribe or update your details at nps.org.au/australian-prescriber

For free copies of the Anaphylaxis wallchart and Switching-antidepressants poster, order online at www.nps.org.au/order\#for-health-professionals
(C) 2019 NPS MedicineWise ABN 61082034393

NPS MedicineWise Disclaimer Reasonable care is taken to provide accurate information at the time of creation. This information is not intended as a substitute for medical advice and should not be exclusively relied on to

manage or diagnose a medical condition. NPS MedicineWise disclaims all liability (including for negligence) for any loss, damage or injury resulting from reliance on or use of this information. 